\title{
Overview on the Recent Technical Recommendations on Acute Pancreatitis
}

\author{
Murli Manohar and Anil Mishra* \\ Department of Medicine, Tulane University School of Medicine, USA
}

Submission: March 29, 2018; Published: May 21, 2018

"Corresponding author: Anil Mishra, Endowed Chair and Professor of Medicine, Tulane Eosinophilic Disorders Centre, and Section of Pulmonary Diseases, Tulane University, School of Medicine, New Orleans, LA, 70112, USA, Tel: 504 988-3840; Fax: 504 988-2144; Email: amishra@tulane.edu

\section{Introduction}

A technical review and clinical practice guidelines and recommendations on the initial management of Acute Pancreatitis (AP) are recently published by Vege and coworkers [1]. The recommendation is an outstanding effort that will be helpful for physicians and scientists to improve their understanding and provide potential treatment options for patients suffering from Acute Pancreatitis (AP). The review summarizes almost all aspects of AP diagnostic and treatment strategies including intravenous hydration, prophylactic antibiotics, End Iscopic Retrograde Chlangio Pancreatogram (ERCP), early feeding, artificial enteral nutritional support, route of feeding, sameadmission versus delayed cholecystectomy, alcohol counseling, and clinical impact of utilizing a risk assessment severity prediction tool. AP is one of the most common reasons for hospitalization with a gastrointestinal condition [2] and it is increasing in prevalence $[3,4]$. The annual incidence of AP varies from 13-45 per 100,000 people in United States [5]; however, the incidence of acute pancreatitis in the US for gallstone related AP is $15 / 100,000$, for non-gallstone related AP is $25 / 100,000$ and for recurrent AP is $10 / 10,0000$.

AP progressively increases in severity with patient age if not diagnosed and properly treated. In the US, both white and black populations are affect by the disease. Overall, most AP patients are middle aged (average age of 58 years) $45 \%$ male, and $80 \%$ white. The most common etiologist are billiary complications, alcohol, and idiopathic. Patients with alcoholic AP are significantly more likely to be younger, male, and black with a history of tobacco use when compared with AP patients with other etiologist. Development of recurrent AP occurs mainly in patients with non-gallstone related AP, although it can develop in patients with gallstone-related pancreatitis if there is a delay or refused cholecystectomy.

AP is generally more prevalent in more developed countries such as the US, Europe, and Japan; however, several reports indicate that the AP incidence is increasing in developing countries. There is variability in the change of AP incidence within countries. The incidence of first-attack AP has relatively unchanged in Taiwan, which differs from the increasing trend observed in most western countries [6]. A retrospective study from Netherland indicates the incidence of acute pancreatitis increased by $28 \%$ in recent years [7]. As observed in western countries, alcohol is the major cause of pancreatitis in South Africa, but the worse prognosis raises the question that better supportive care may improve overall survival of AP patients [8]. In Italy, a multicenter study of 1005 reportedAP patients (males $53 \%$ and females $47 \%$ ) with mean age $59.6 \pm 20$ years indicated $5 \%$ mortality rate [9]. In Swedish population AP is reported 7.6\% per year incidence of acute pancreatitis with gallstone-related pancreatitis however, alcohol-related pancreatitis was decreased by minus (-) 5.1\% per year [3]. Acute inflammation and repeated episodes of acute pancreatitis lead to chronic disease, which is characterized by fibrosis and calcification $[10,11]$.

Regarding the question raised for the role of intravenous hydration in initial management, has several reasons to induce pancreatic necrosis and abnormal functioning of pancreas. This fluid therapy appears to be helpful, as reported that aggressive fluid administration during the first 24 hours in severe cases decreases the rate of morbidity and mortality [12]. The International Association of Pancreatology (IAP) and American Pancreatic Association (APA) guidelines provided directions for early and vigorous Ringer's lactate administration for the initial fluid resuscitation in AP. However, the concerns remain regarding fluid therapy for the initial management of acute pancreatitis related to the type of fluid, the rate of fluid delivery and the parameters to gauge effectiveness. We agree with the recent recommendations of Vege and co-workers [1] that intravenous hydration in AP will be considered for the enrolment of only consecutive patients. 
The role of prophylactic antibiotics in severe acute pancreatitis (SAP) and necrotizing AP is well discussed in the technical review. Pancreatic and extra-pancreatic necrosis leading to infections of other tissues is very common in SAP. Welldesigned meta-analyses $[13,14]$ and double blind trials $[15,16]$ indicated no potential benefits of prophylactic antibiotics in SAP. Moreover, the use of antibiotics in SAP may promote bacterial infection with pancreatic necrosis. The review did not consider the role of inflammatory mediators released from immune cells in promoting cell death and necrosis in AP. Several reports indicate the in falmmatory immune cells including mast cells, neutrophils and eosinophils accumulate in AP and thereby contribute to disease pathogenesis and possibly mediate SAP. The technical review has not address the detection or control of these innate immune cells in pancreatic inflammation, which needs attention in future studies. Other recommendations for future studies include a large sample size with a multicenter trial design.

ERCP is a procedure that combines upper gastrointestinal (GI) endoscopy and x-rays to treat problems of the bile and pancreatic ducts. ERCP, invasive procedure withseveral complications, is also performed on patients having gallstoneassociated AP. The complications of ERCP including infection, pancreatitis, hemorrhage, and perforation can occur even with expert. Factors such as patient selection, skill of the operator, and the complexity of procedure, can add to the risks of ERCP [17].

Additionally, ERCP may promote microbial infection $[18,19]$ and about $2 \%$ of ERCP cases have reported post sphincterotomy bleeding $[20,21]$, whereas, up to $30 \%$ of patients experienced immediate bleeding [22]. Although several reports suggest that ERCP is generally safe, but the role of urgent ERCP in acute biliary pancreatitis is a matter of concern. There is a need to modify our approach by using non invasive tests those avoid the complications ERCP. These non invasive possibilities include Magnetic Resonance Cholangio Pancreatography (MRCP) i.e. a type of Magnetic Resonance Imaging (MRI) and endoscopic ultrasound before conducting ERCP in patients with acute biliary pancreatitis. The technical review [1] strongly recommends following the inclusion and exclusion criteria, as well as definitions for persistent biliary obstruction, cholangitis, and predicted severe biliary AP for future clinical trials. It also recommends observation for 24 hours to allow spontaneous passage of a stone and 48 hours to ensure there is no prolonged biliary obstruction. However, the recommendation has not given any attention to the drawback of an ERCP that may not to provide sufficient tissue for pathological examination. That may be a problem for the patient in the future if immune cell accumulation in the tissue is not detected.

Nutritional interventions in acute pancreatitis maintain the integrity of the gut barrier in the small intestine, which is one of the most important aspects of the initial phase of SAP treatment. In addition, nutrition and nutritional supplements can also provide important immune modulator and antioxidant effects. Generally, AP patients are maintained on 'Nil Per Os' or nothing by mouth to allow the pancreas to rest until the resolution of pain or normalization of pancreatic serum enzymes [23].

As an alternative, enteral nutrition (EN) or parenteral nutrition (PN) has been recommended. However, both routes have potential risks of infection and other complications. Therefore, optimal nutritional support in AP is under debate for decades because dietary restrictions exacerbate the patient's malnutrition, which leads to catabolism, bacterial translocation and necrosis [24,25]. The recommendations from Vege and co workers [1] regarding feeding related to timing, optimal route (oral vs. NG vs. NJ routes), rate, total calories and composition are very important for patients with severe and necrotizing AP and these recommendations should be considered in future clinical trials.

\section{Conclusion}

The current review of AP did not mention the role of food allergens in the AP disease pathogenesis. AP patients should be referred to an allergy clinic to rule out the possibility of food allergen-induced AP. We recently published a review that summarizes the reports available on food-induced acute pancreatitis and that is because of food allergy [26]. Therefore we suggest to include the testing of food allergy during the initial management of patients with acute pancreatitis. We recently published possible mechanisms of AP promotion by food allergies [26]. The initial management of acute pancreatitis patients should include testing for food allergy.

\section{References}

1. Vege SS, DiMagno MJ, Forsmark CE, Martel M, Barkun AN (2018). Initial Medical Treatment of Acute Pancreatitis: American Gastroenterological AssociationInstitute Technical Review. Gastroenterology. 2018 154(4):1103-1139.

2. http://wwwgastroorg/patient-care/AGA_acute_pancreatitis_ Appendix_for_public_commentpdf2017.

3. Peery AF, Dellon ES, Lund J, Crockett SD, Mc Gowan CE, et al. (2012) Burden of gastrointestinal disease in the United States: 2012 update. Gastroenterology 143(5): 1179-1187.

4. Lindkvist B, Appelros S, Manjer J, Borgstrom A (2004) Trends in incidence of acute pancreatitis in a Swedish population: is there really an increase? Clin Gastroenterology Hepatol 2(9): 831-837.

5. Spanier B, Bruno MJ, Dijkgraaf MG (2013) Incidence and mortality of acute and chronic pancreatitis in the Netherlands: a nationwide recordlinked cohort study for the years 1995-2005. World J Gastroenterol 19(20): 3018-3026.

6. Yadav D, Lowenfels AB (2013) The epidemiology of pancreatitis and pancreatic cancer. Gastroenterology 144(6): 1252-1261.

7. Shen HN, Lu CL, Li CY (2012) Epidemiology of first-attack acute pancreatitis in Taiwan from 2000 through 2009: a nationwide population-based study. Pancreas 41(5): 696-702.

8. Eland IA, Sturkenboom MJ, Wilson JH, Stricker BH (2000) Incidence and mortality of acute pancreatitis between 1985 and 1995. Scand J Gastroenterol 35(10): 1110-1116. 
9. Anderson F, Thomson SR, Clarke DL, Loots E (2008) Acute pancreatitis: demographics, aetiological factors and outcomes in a regional hospital in South Africa. S Afr J Surg 46(3): 83-86.

10. Cavallini G, Frulloni L, Bassi C, Gabbrielli A, Castoldi L, et al. (2004) Prospective multicentre survey on acute pancreatitis in Italy (ProInfAISP): results on 1005 patients. Dig Liver Dis 36(3): 205-211.

11. Manohar MVA, Venkateshaiah SU, Mishra A (2017) Immunological responses involved in promoting acute and chronic pancreatitis. Clinical Immunology \& Research 1: 1-8.

12. Manohar M, Verma AK, Venkateshaiah SU, Sanders NL, Mishra A (2017) Pathogenic mechanisms of pancreatitis. World J Gastrointest Pharmacol Ther 8(1): 10-25.

13. Gardner TB, Vege SS, Chari ST, Petersen BT, Topazian MD, et al. (2009) Faster rate of initial fluid resuscitation in severe acute pancreatitis diminishes in-hospital mortality. Pancreatology 9(6): 770-776.

14. Lim CL, Lee W, Liew YX, Tang SS, Chlebicki MP, et al. (2015) Role of antibiotic prophylaxis in necrotizing pancreatitis: a meta-analysis. J Gastrointest surgy 19(3): 480-491.

15. Villatoro E, Mulla M, Larvin M (2010) Antibiotic therapy for prophylaxis against infection of pancreatic necrosis in acute pancreatitis. Cochrane Database Syst Rev 12(5): CD002941.

16. Dellinger EP, Tellado JM, Soto NE, Ashley SW, Barie PS, et al. (2007) Early antibiotic treatment for severe acute necrotizing pancreatitis: a randomized, double-blind, placebo-controlled study. Ann surg 245(5): 674-683.

17. Isenmann R, Runzi M, Kron M, Kahl S, Kraus D, et al. (2004) Prophylactic antibiotic treatment in patients with predicted severe acute pancreatitis: a placebo-controlled, double-blind trial. Gastroenterology 126(4): 997-1004.
18. Szary NM, Al-Kawas FH (2013) Complications of endoscopic retrograde cholangiopancreatography: how to avoid and manage them. Gastroenterol Hepatol (N Y) 9(8): 496-504.

19. Kullman E, Borch K, Lindstrom E, Ansehn S, Ihse I, et al. (1992) Bacteremia following diagnostic and therapeutic ERCP. Gastrointest Endosc 38(4): 444-449.

20. Parker HW, Geenen JE, Bjork JT, Stewart ET (1979) A prospective analysis of fever and bacteremia following ERCP. Gastrointest Endosc 25(3): 102-103.

21. Freeman ML, Nelson DB, Sherman S, Haber GB, Herman ME, et al. (1996) Complications of endoscopic biliary sphincterotomy. N Engl J med 335(13): 909-918.

22. Loperfido S, Angelini G, Benedetti G, Chilovi F, Costan F, et al. (1998) Major early complications from diagnostic and therapeutic ERCP: a prospective multicenter study. Gastrointest Endosc 48(1): 1-10.

23. Ferreira LE, Baron TH (2007) Post-sphincterotomy bleeding: who, what, when, and how. Ame J GastroenteroL 102(12): 2850-2858.

24. Banks PA, Freeman ML, Practice Parameters Committee of the American College of G (2006) Practice guidelines in acute pancreatitis. Am J Gastroenterol 101(10): 2379-2400.

25. Fritz S, Hackert T, Hartwig W, Rossmanith F, Strobel O, et al. (2010) Bacterial translocation and infected pancreatic necrosis in acute necrotizing pancreatitis derives from small bowel rather than from colon. Am J Surg 200(1): 111-117.

26. Pan LL, Li J, Shamoon M, Bhatia M, Sun J (2017) Recent advances on nutrition in treatment of acute pancreatitis. Front Immunol 8: 762.

27. Manohar M, Verma AK, Upparahalli Venkateshaiah S, Goyal H, Mishra A (2017) Food-induced acute pancreatitis. Dig Dis Sci 62(12): 32873297.

\section{Your next submission with JuniperPublishers will reach you the below assets}

- Quality Editorial service

- Swift Peer Review

- Reprints availability

- E-prints Service

- Manuscript Podcast for convenient understanding

- Global attainment for your research

- Manuscript accessibility in different formats

( Pdf, E-pub, Full Text, audio)

- Unceasing customer service

Track the below URL for one-step submission https://juniperpublishers.com/online-submission.php 